\title{
A parametric study on the decolorization and mineralization of C.I. Reactive Red 141 in water by heterogeneous Fenton-like oxidation over FeZSM-5 zeolite
}

\author{
Ceyda Yaman and Gönül Gündüz*
}

\begin{abstract}
In this study, the heterogeneous Fenton-like degradation of Reactive Red 141 (RR141) in water was investigated over iron containing ZSM-5 zeolite (Si/AI = 42) prepared by ion-exchange (FeZSM-5 (42)). The catalyst was characterized by XRD, SEM, FTIR, TPR, and ICP-AES measurements. The effects of the initial concentrations of the dye and $\mathrm{H}_{2} \mathrm{O}_{2}$, the initial $\mathrm{pH}$ of the solution, catalyst loading, and the reaction temperature were investigated on heterogeneous Fenton-like degradation of RR141. The reduction of the solution initial pH from ca. 7.0 to ca. 3.5 had a positive effect on color removal. A complete color removal was achieved with all the $\mathrm{H}_{2} \mathrm{O}_{2}$ concentrations in the range of 0.007 - $0.067 \mathrm{M}$ over the FeZSM-5 (42) catalyst after $2 \mathrm{~h}$ of reaction. The COD reduction increased from $52 \%$ to $81 \%$ with an increase in the amount of the catalyst. The COD reduction was affected positively with the increase in temperature from $298 \mathrm{~K}$ through $313 \mathrm{~K}$ to $323 \mathrm{~K}$ and then to $333 \mathrm{~K}$. The initial decolorization rate was described by the equation: $-r_{A 0}=9.4^{*} 10^{4} e^{-38.8 / R T} C_{R R 141,0} C_{H 2 O 2,0}^{0.184}$ with an $\mathrm{H}_{2} \mathrm{O}_{2}$ concentration range of 0.007 $\mathrm{M}-0.033 \mathrm{M}$ (where $\mathrm{R}$ is in $\mathrm{kJ} / \mathrm{mol})$.
\end{abstract}

Keywords: Reactive red 141, Heterogeneous Fenton-like oxidation, Fe-ZSM-5 zeolite catalyst

\section{Background}

Sulfonated and unsulfonated azo dyes have a negative aesthetic effect on the wastewater that is highly colored even at a low concentration of dye. On the other hand these dyes are toxic, carcinogenic and mutagenic. It is difficult to remove azo dyes in wastewater produced by textile industries using biological, physical and chemical treatment methods because of the chemical stability of these dyes, the high cost of the processes, and also disposal problems. Therefore, it is necessary to find an effective method for the wastewater treatment of reactive azo dyes. In the last decade, attention has focused on the Advanced Oxidation Processes (AOP) that is based on the generation of highly reactive hydroxyl radicals.

\footnotetext{
* Correspondence: gonul.gunduz@ege.edu.tr

Chemical Engineering Department, Ege University, 35100 Bornova, İzmir,
} Turkey

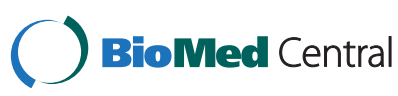

(C) 2015 Yaman and Gündüz; licensee BioMed Central. This is an Open Access article distributed under the terms of the Creative Commons Attribution License (http://creativecommons.org/licenses/by/4.0), which permits unrestricted use, distribution, and reproduction in any medium, provided the original work is properly credited. The Creative Commons Public Domain Dedication waiver (http://creativecommons.org/publicdomain/zero/1.0/) applies to the data made available in this article, unless otherwise stated.
Among them, heterogeneous Fenton's reaction is very promising because it is a cost-effective method with a high reaction yield and regeneration of the catalyst is possible. The removal of the catalyst from the purified water is easy and a narrow range of $\mathrm{pH}$ values at which the reaction occurs is not required. On the other hand, leaching of iron ions from the solid catalyst is limited [1-16]. Heterogeneous Fenton-type catalysts have been developed by incorporating transitional metal cations such as iron ions or iron oxides into porous supports such as zeolites and pillared clays [17-21]. In the presence of $\mathrm{H}_{2} \mathrm{O}_{2}$, hydroxyl radicals $\left(\mathrm{OH}^{*}\right)$ are produced by interaction of $\mathrm{H}_{2} \mathrm{O}_{2}$ with the iron (II) species present on the porous support. The main reaction mechanism of heterogeneous Fenton process is described as follows [22-26]:

$$
\mathrm{X}-\mathrm{Fe}^{2+}+\mathrm{H}_{2} \mathrm{O}_{2} \rightarrow \mathrm{X}-\mathrm{Fe}^{3+}+\mathrm{OH}^{-}+\mathrm{HO}
$$

where $\mathrm{X}$ presents the surface of the catalyst. Iron (III) can then react through Equations 2-4 with hydrogen 
peroxide in order to regenerate iron (II) supporting the Fenton process:

$$
\begin{aligned}
& \mathrm{X}-\mathrm{Fe}^{+3}+\mathrm{H}_{2} \mathrm{O}_{2} \rightleftarrows \mathrm{X}-\mathrm{FeOOH}^{2+}+\mathrm{H}^{+} \\
& \mathrm{X}-\mathrm{FeOOH}^{2+} \rightarrow \mathrm{HO}_{2} \cdot+\mathrm{X}-\mathrm{Fe}^{2+} \\
& \mathrm{X}-\mathrm{Fe}^{3+}+\mathrm{HO}_{2} \rightarrow \mathrm{X}-\mathrm{Fe}^{2+}+\mathrm{O}_{2}+\mathrm{H}^{+}
\end{aligned}
$$

The hydroperoxyl radicals $\left(\mathrm{HO}_{2}\right)$ generated in Eq.3 are less reactive than the $\mathrm{OH}$ species. In the application of heterogeneous Fenton-like oxidation to dye degradation, the following reactions take place: Firstly, the formed oxidative radicals $\left(\mathrm{OH}\right.$ and $\left.\mathrm{HO}_{2}\right)$ react with the activated dye molecules to produce intermediate products and then mineralization products $\left(\mathrm{H}_{2} \mathrm{O}+\mathrm{CO}_{2}\right)$ through Eqs. 5-6:

$$
\begin{aligned}
& \mathrm{X}-\mathrm{Fe}^{3+}+\text { dye } \rightarrow \mathrm{X}-\mathrm{Fe}^{2+}+\text { dye } \\
& \text { Oxidative radicals }+ \text { dye } \\
& \text { products } \rightarrow \mathrm{CO}_{2}+\mathrm{H}_{2} \mathrm{O} \text { Intermediate }
\end{aligned}
$$

Decolorization of the dye is a result of $\mathrm{N}=\mathrm{N}$ bond destruction with the addition of $\mathrm{OH}$. The mineralization of dye is the total oxidation of the intermediate products to $\mathrm{CO}_{2}$ and $\mathrm{H}_{2} \mathrm{O}$ and it is slower than color removal because of the priority of the $\mathrm{OH}$ attack on the $\mathrm{N}=\mathrm{N}$ bonds [1].

C.I. Reactive Red 141 (RR141) is a sulfonated, bright red color diazo reactive textile dye and is widely used for the dyeing processes in the textile industry. Procion Red HE7B and C.I. Reactive Red 141 are the commercial names of the dye. Its empirical formula is $\mathrm{C}_{52} \mathrm{H}_{22} \mathrm{Na}_{8} \mathrm{O}_{26} \mathrm{~S}_{8} \mathrm{C}_{12} \mathrm{~N}_{14}$ and is composed of two monochlorotriazine reactive groups. It has a molecular weight of $1774 \mathrm{~g} / \mathrm{mol}$ and its chemical structure is given in Figure 1. The adsorption spectra of RR141 is characterized by two main bands, one in the visible region $(\lambda \max =543 \mathrm{~nm})$ and the other in the $\mathrm{UV}$ region $(\lambda \max =288 \mathrm{~nm})$. In the heterogeneous Fenton-like oxidation of RR141, hydroxyl radical attack on the $\mathrm{N}=\mathrm{N}$ bonds occurs at $543 \mathrm{~nm}$ and this band is responsible for the chromophoric components in the dye.

The degradation of RR141 has been investigated by biodegradation [27-29], by adsorption [22,30,31], by homogeneous Fenton's reaction, by non-catalytic or

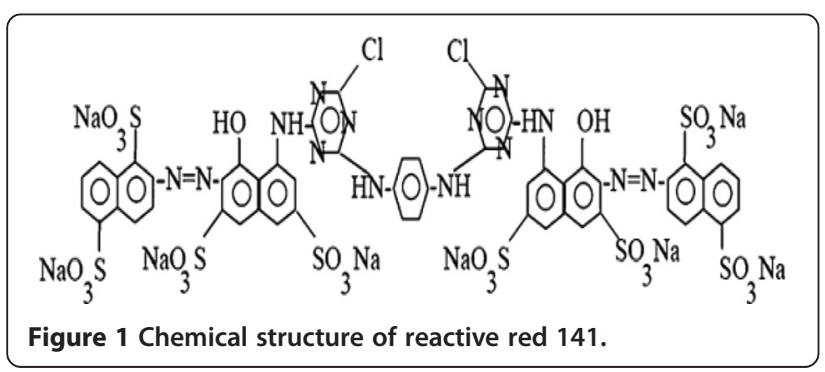

catalytic photooxidation [32-41], by electrochemical oxidation with conductive-diamond anode [42], and by ultrasound [1]. Few studies have been reported on the heterogeneous Fenton-like degradation of C.I. Reactive Red 141 to date. In one study, iron oxide particles recovered from acid mine drainage were used as an adsorbent or as a catalyst in the oxidation of RR141 through a Fenton-like mechanism to remove the dye from the aqueous solution [22]. However, the main aim of that study was to investigate the dye-adsorption capacity of iron oxide rather than its catalytic effect in the heterogeneous Fenton-like oxidation of dye. Only one experiment has been carried out for dye degradation by heterogeneous Fenton's reaction and a TOC removal of around $3 \%$ could only be achieved.

Conventional processes such as adsorption, coagulation/flocculation (CF) etc., may be costly, ineffective and produce a high amount of secondary wastes. CF is still not good enough to be used in industry even when it is combined with microfiltration or ultrafiltration. However, catalytic methods such as heterogeneous Fentonlike oxidation result in permanent chemical degradation of dyes. This process is still simple, non-expensive, a promising, and attractive treatment method for the effective decolorization and degradation of dyes when compared with the conventional processes [25-43].

Many studies are found in literature on the removal of dyes using Fe-ZSM-5 [3,23,24,44], Fe-Y [2,25,45-48], and Fe-clay [26,49-52] catalysts by several advanced oxidation techniques. The catalytic activity and stability of these catalysts depend on the synthesis method in addition to their composition and framework structure. The leakage of iron ions from the support is the other important factor to be considered in dye degradation over an iron containing support: because iron leaching from the catalyst causes a new pollution of the treated water. The studies showed that iron containing ZSM-5 zeolite exhibited better catalytic activity and stability than iron-containing Y zeolites. On the other hand, the activity of iron-containing clay catalysts in the degradation of dyes depends on the careful selection of the preparation method and calcination conditions. However, till now no a detailed parametric study including decolorization kinetics has not been reported on the heterogeneous Fenton-like degradation of dyes on iron containing ZSM-5 zeolites. The objectives of this study are to: (1) investigate the influence of the reaction conditions of the heterogeneous Fenton-like oxidation and optimize them, (2) investigate the decolorization kinetics, and (3) investigate the leakage of iron ions in the reaction for the stability of the catalyst.

Our group previously published a study [53] on the degradation of RR141 using the heterogeneous Fenton-like process over iron containing ZSM-5 zeolites. That work 
included the preparation of the catalysts by ion-exchange or hydrothermal synthesis and their characterization studies by XRD, SEM, FTIR, ICP-AES, TPR, and nitrogen adsorption. The catalytic activity screening tests of the prepared catalysts were accomplished to determine the catalyst with the highest activity in the degradation of RR141 by heterogeneous Fenton-like oxidation reaction. The highest color removal (97\%) was achieved by the catalyst prepared by ion exchange with a silicon/aluminum ratio of 42 zeolite (FeZSM-5(42)). The above mentioned objectives of the presented study was investigated over that iron-containing ZSM-5 zeolite catalyst. The presented study is novel and unique from these points of view.

\section{Methods}

\section{Preparation of the catalysts}

Ion exchange was used for the preparation of the iron containing the ZSM-5 zeolite catalyst. The method of Schwidder et al. [54] was applied with minor modifications [21] for the ion-exchange. The ZSM-5 zeolite with silicon/alumina $=42$ was obtained from Süd-Chemie AG (Germany). An iron exchange of $98.9 \%$ could be achieved. The catalyst was coded as FeZSM-5 (42).

\section{Catalyst characterization}

The prepared catalyst was characterized by nitrogen adsorption, X-ray diffraction patterns (XRD), scanning electron microscope (SEM), Fourier transform-infrared (FTIR) spectrometer, inductively coupled plasma atomic emission spectrometer (ICP-AES), and by temperature programmed reduction (TPR) measurements. The precise procedures for the characterization of the catalyst are described in Ref [53].

\section{Heterogeneous Fenton-like oxidation of RR141}

C.I. Reactive Red 141 (Procion Red H-E7B) was purchased from Dystar (Germany) with a dye content of $>85 \%$ and was used as received without further purification. The heterogeneous Fenton-like degradation of RR141 was carried out under isothermal conditions in a temperature controlled shaded glass batch reactor with a volume of $470 \mathrm{~mL}$ equipped with a mechanical stirrer at ca. $280 \mathrm{rpm}$ (Heidolph, Germany) and a pH electrode (Mettler Toledo). Figure 2 presents the picture of the experimental set-up. In a typical run, $0.15 \mathrm{dm}^{3}$ of aqueous dye solution $(0.1$ g-dye $/ \mathrm{dm}^{3}$-soln $=5.64 \times 10^{-5} \mathrm{M}$ ) was placed into the reactor and the temperature was adjusted to $333 \mathrm{~K}$. When the temperature reached to $333 \mathrm{~K}$, the $\mathrm{pH}$ of the dye solution was measured and $0.15 \mathrm{~g}$ of catalyst $\left(1 \mathrm{~g}\right.$-cat $/ \mathrm{dm}^{3}-$ soln. $)$ was introduced into the solution under continuous stirring. After the adsorption equilibrium was established (roughly in 10-15 $\mathrm{min}$ ) the solution was analyzed to determine the dye removal by adsorption. Then a solution of $35 \% \mathrm{H}_{2} \mathrm{O}_{2}$ (Merck, Germany) (40 mmol/0.15 dm $\mathrm{dm}^{3}$ solution, namely

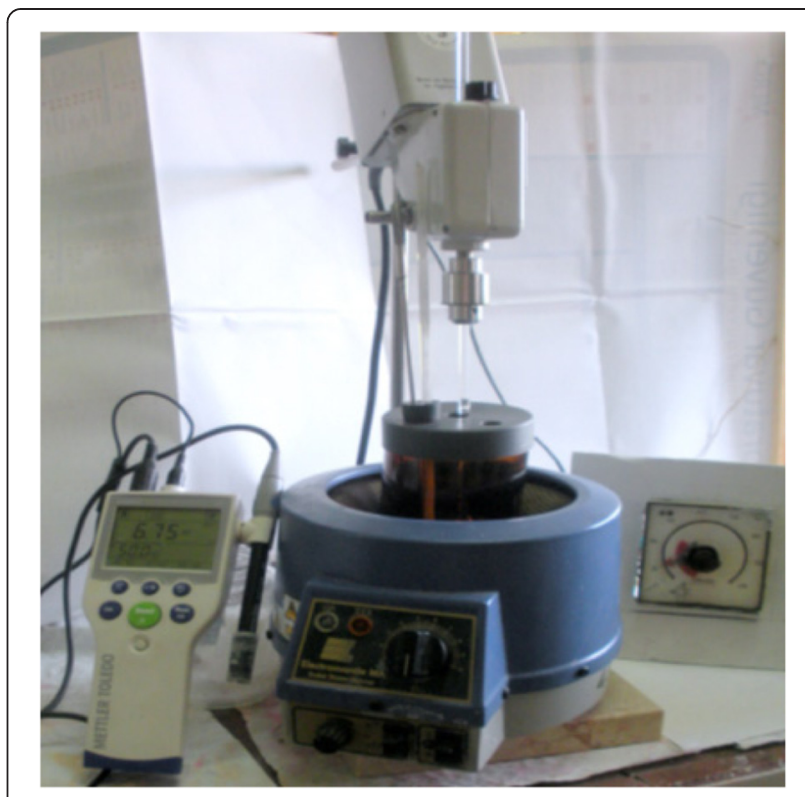

Figure 2 Experimental set-up.

$0.267 \mathrm{M}$ ) was added to the dye solution. After the addition of $\mathrm{H}_{2} \mathrm{O}_{2}$, the $\mathrm{pH}$ of the solution was again measured. This was recorded as the starting time of the reaction. The samples taken periodically were centrifuged for $0.5 \mathrm{~h}$ to remove the catalyst and kept at $273 \mathrm{~K}$ to stop the reaction before the analysis with the UV spectrophotometer (Jasco 7800 $\mathrm{UV} / \mathrm{vis}$ ).

The decrease of the intensity of the band at $543 \mathrm{~nm}$ was used as a measure of decolorization degree. The reduction in the chemical oxygen demand (COD) of the dye solution was determined using a Lovibond (Germany) Checkit Direct COD Vario device for each run after a reaction time of $2 \mathrm{~h}$.

The blank run with the above conditions, but without $\mathrm{H}_{2} \mathrm{O}_{2}$ showed that dye removal by adsorption was not greater than $3 \%$ and $21 \%$ in $15 \mathrm{~min}$ and $120 \mathrm{~min}$ of reaction, respectively. A color removal of $11 \%$ could be achieved in the presence of $\mathrm{H}_{2} \mathrm{O}_{2}$ only in 2 hour of reaction.

Each experiment was conducted in duplicate and the standard deviation of the average of the independent runs for color removal changed in the range of \pm 0.51 to \pm 1.29 .

\section{Results and discussion}

\section{Catalyst characterization studies}

The X-ray diffraction patterns of the FeZSM-5 catalyst sample showed the typical diffractrograms of the MFI structure $\left(2 \theta=7-9^{0}\right.$ and $\left.23-25^{\circ}\right)$. The incorporation of iron in the MFI lattice did not damage the zeolite structure [53].

The SEM images of the catalyst sample depicted that the crystallites in the FeZSM-5 (42) sample were a spherical shape (Figure 3). 


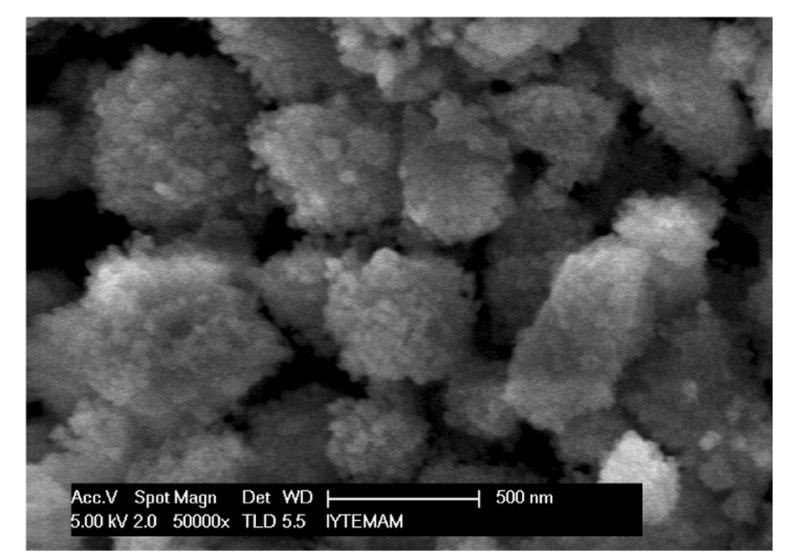

Figure 3 SEM image of the catalyst.

Iron content and $\mathrm{Si} / \mathrm{Al}$ ratio of the catalyst were determined with the ICP-AES method and found to be $4.98 \mathrm{wt}$ $\%$ and 42.8 , respectively. The BET surface area, total pore volume, average pore diameter and micropore area of the catalyst were found to be $469 \mathrm{~m}^{2} / \mathrm{g}, 0.321 \mathrm{~cm}^{3} / \mathrm{g}, 0.73 \mathrm{~nm}$ (using the Horvath-Kawazoe method), and $236 \mathrm{~m}^{2} / \mathrm{g}$, respectively.

The FTIR spectra of the catalyst showed bands at 450, $550,800,1100,1225$, and $1650 \mathrm{~cm}^{-1}$ which were assigned to different vibrations of the tetrahedral and framework structure of the ZSM-5 zeolite [53].

The temperature-programmed reduction with hydrogen $\left(\mathrm{H}_{2}-\mathrm{TPR}\right)$ of the catalyst showed that a major hydrogen consumption peak was obtained at $397 \mathrm{~K}$ which reflected the reduction of out of framework iron oxides [53].

\section{Influence of the initial $\mathrm{pH}$ of solution on the degradation of dye}

The effect of solution $\mathrm{pH}$ on the degradation of dye was investigated at an initial dye $\mathrm{pH}$ of $\mathrm{ca} .7$ and a $\mathrm{pH}$ of 3.5 which was regulated by the addition of $0.1 \mathrm{~N}$ sulphuric acid to the dye solution.

Figure 4 shows the effect of the solution $\mathrm{pH}$ on the color and COD removals for RR141 degradation with the catalyst. The reduction of $\mathrm{pH}$ to around 3.5 positively affected

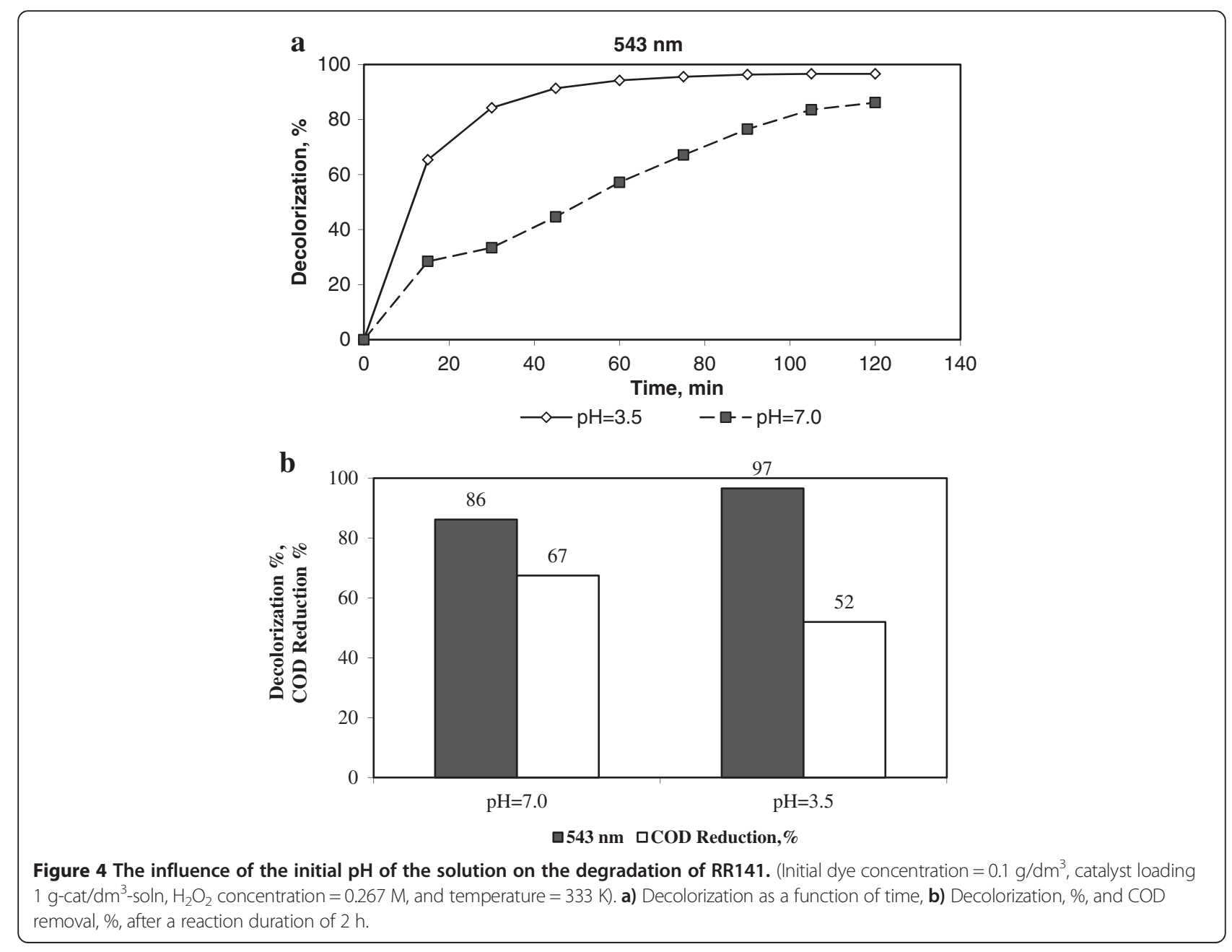


the color removal. The acidic environment increased the decolorization degree of the dye from $86 \%$ to $97 \%$ after a reaction duration of $2 \mathrm{~h}$. The $\mathrm{pKa}$ of the sodium sulfonate groups of the dyes is very low $(<1)$, therefore, the RR141 is expected to exist as anionic groups $\left(-\mathrm{SO}_{3}^{-}\right)$at a $\mathrm{pH}>1.0$. On the other hand, the interaction between the anionic groups of dye and surface acid sites of the Fe-ZSM-5 zeolite catalysts becomes stronger at a low $\mathrm{pH}$. The observed increase in decolorization at a low $\mathrm{pH}$ can be attributed to a greater adsorption of dye on the catalyst surface and consequently it results in a higher decolorization of the dye [40]. However, a decrease in COD removal from 67\% to $52 \%$ was observed with the regulation of the solution $\mathrm{pH}$ to a ca. 3.5. This may be due to the formation of intermediates such as monoazo, naphthalene, and naphthol disulfonic acid intermediates whose degradation is hindered at acidic $\mathrm{pH}[20,29]$.

The amount of iron loss from the catalyst into the solution was determined by measuring the iron concentration in the solution after a reaction duration of $2 \mathrm{~h}$, with an atomic absorption spectrophotometer (Varian 10 plus). The leaching of iron cations from the zeolite into the solution depended strongly on the $\mathrm{pH}[4]$. As expected, with the regulation of $\mathrm{pH}$ from 7 to about 3.5 the iron leaching increased from $0.3 \times 10^{-3} \mathrm{~g} / \mathrm{dm}^{3}$ to $0.9 \times 10^{-3} \mathrm{~g} /$ $\mathrm{dm}^{3}$. It means that iron loss changed from $0.59 \%$ to $1.77 \%$. As seen, the iron leaching was considerably low (being below the EU directives of $<2 \times 10^{-3} \mathrm{~g} / \mathrm{dm}^{3}$ ).

\section{Influence of the hydrogen peroxide concentration on the degradation of dye}

The effect of the $\mathrm{H}_{2} \mathrm{O}_{2}$ concentration on the degradation of RR141, while maintaining constant all the other operating parameters (catalyst loading: $1 \mathrm{~g}$-cat $/ \mathrm{dm}^{3}-$ soln., initial $\mathrm{pH} \sim 3.5$, initial concentration of dye $=0.1 \mathrm{~g}$-dye $/ \mathrm{dm}^{3}$-soln., temperature $=333 \mathrm{~K}$ ) was investigated and is given in Figure 5. The increase in $\mathrm{H}_{2} \mathrm{O}_{2}$ concentration from $0.007 \mathrm{M}$ to $0.017 \mathrm{M}$ and to $0.033 \mathrm{M}$ positively affected the initial rate of color removal (Figure 5a.). This result is expected because of the increase of the $\mathrm{OH}$ radicals produced with the increasing amount of $\mathrm{H}_{2} \mathrm{O}_{2}$, Eq.1. Nevertheless the increase in $\mathrm{H}_{2} \mathrm{O}_{2}$ concentration from $0.033 \mathrm{M}$ to $0.067 \mathrm{M}$ and to $0.267 \mathrm{M}$ slowed the initial decolorization of RR141. A complete color removal was
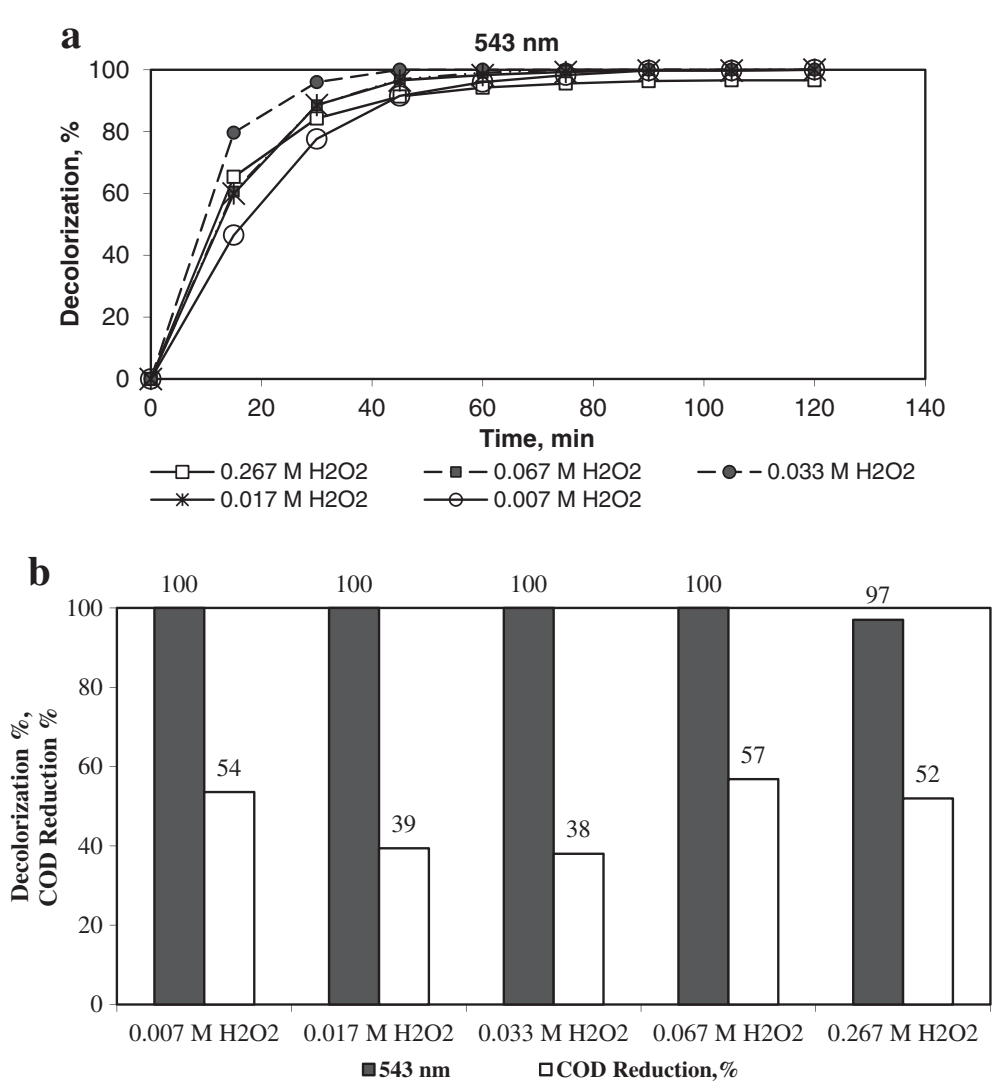

Figure 5 The influence of the initial $\mathrm{H}_{2} \mathrm{O}_{2}$ amount on the degradation of RR141. (Initial dye concentration $=0.1 \mathrm{~g} / \mathrm{dm}^{3}$, catalyst loading 1 g-cat $/ \mathrm{dm}^{3}$-soln, initial $\mathrm{pH} \sim 3.5$, and temperature $=333 \mathrm{~K}$ ). a) Decolorization as a function of time, b) Decolorization, \%, and COD removal, \%, after a reaction duration of $2 \mathrm{~h}$. 
achieved with all the initial concentrations of $\mathrm{H}_{2} \mathrm{O}_{2}$ studied, except with $0.267 \mathrm{M}(97 \%)$ after $2 \mathrm{~h}$ of oxidation. The slight decrease in the initial decolorization of RR141 with an increasing $\mathrm{H}_{2} \mathrm{O}_{2}$ can be attributed to the reaction between the $\mathrm{H}_{2} \mathrm{O}_{2}$ and generated hydroxyl radicals to produce less reactive hydroperoxyl radicals $\left(\mathrm{HO}_{2}\right)$ :

$$
\mathrm{H}_{2} \mathrm{O}_{2}+\mathrm{OH} \rightarrow \mathrm{HO}_{2}+\mathrm{H}_{2} \mathrm{O}
$$

The dominant response from the two opposite effects given in Equations 1 and 7 directs the reaction. Similar results have been reported by Neamtu et al. [2] and Ramirez et al. [4], in the Fenton-like oxidation of Procion Marine H-EXL and Orange II, respectively.

Figure $5 \mathrm{~b}$ presents the percentages of decolorization and COD removal in the degradation of RR141 after a reaction time of $2 \mathrm{~h}$. COD reduction reached $57 \%$ in the presence of $0.067 \mathrm{M}$ of $\mathrm{H}_{2} \mathrm{O}_{2}$, while it was $54 \%$ at a dose of $0.007 \mathrm{M} \mathrm{H}_{2} \mathrm{O}_{2}$ and decreased to $38 \%$ with the increase in $\mathrm{H}_{2} \mathrm{O}_{2}$ concentration from $0.007 \mathrm{M}$ to $0.033 \mathrm{M}$. A COD removal of $52 \%$ was obtained at a dose of $0.267 \mathrm{M} \mathrm{H}_{2} \mathrm{O}_{2}$. The COD removal is significantly lower than the color removal at all doses of $\mathrm{H}_{2} \mathrm{O}_{2}$. This result signifies the priority of the $\mathrm{OH}^{\cdot}$ attack on the $\mathrm{N}=$ $\mathrm{N}$ bonds and the slower destruction of the aromatic/olefinic carbons in the dye [1]. For cost considerations, the optimum $\mathrm{H}_{2} \mathrm{O}_{2}$ concentration can be selected as $0.007 \mathrm{M}$.

In literature, the COD (chemical oxygen demand), TOC (Total Organic Carbon), and DOC (dissolved organic carbon) removals were measured in the degradation of RR141 by several advanced oxidation techniques. For instance a TOC removal of about $3 \%$ was achieved in the heterogeneous Fenton-like oxidation of RR141 over iron oxides particles recovered from acid mine drainage [22].

A $17 \%-23 \%$ TOC removal was achieved in the degradation of RR141 by the ferrioxalate-Fenton/UV-A and $\mathrm{TiO}_{2} / \mathrm{UV}$-A processes [32].

A 100\% DOC removal was obtained for RR141 after a 90 min treatment under homogeneous Fenton assisted solar light [34].
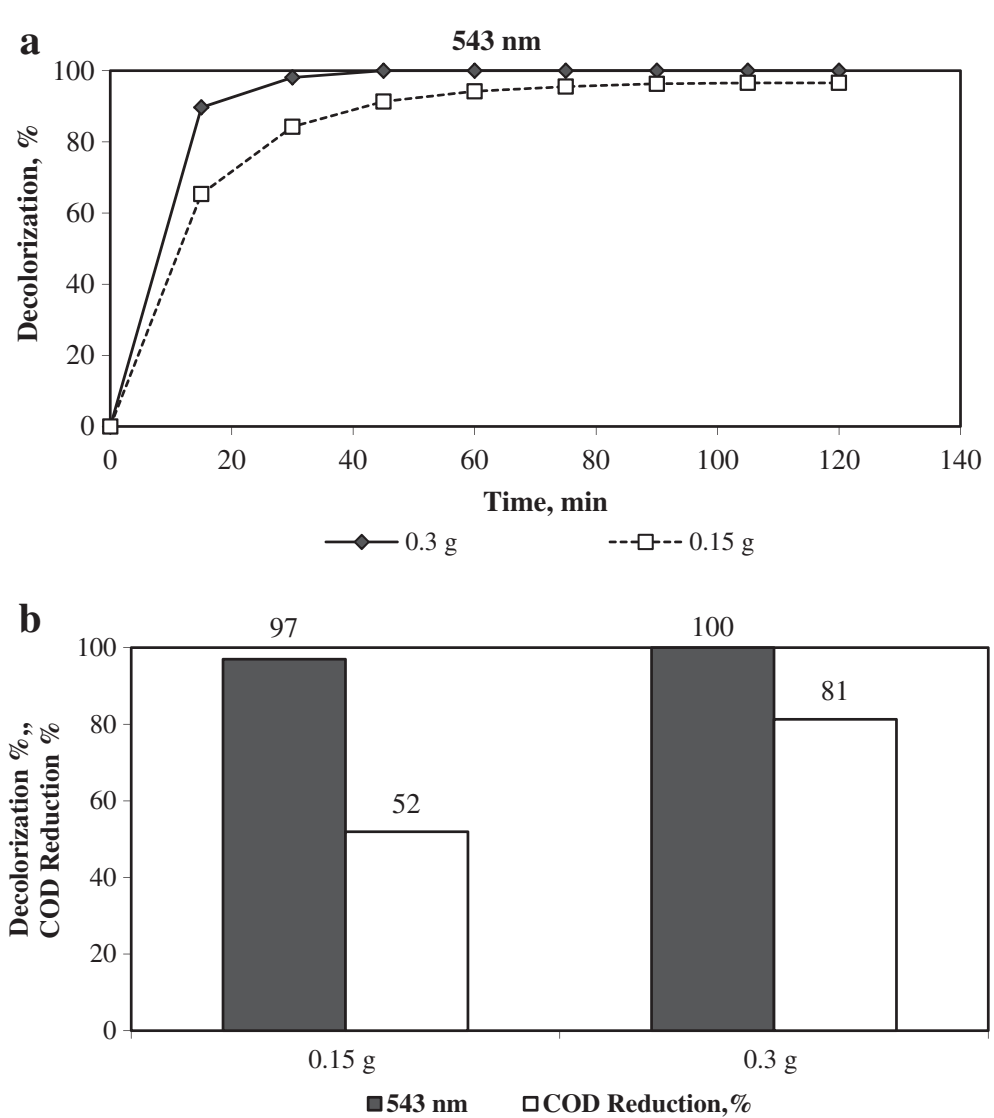

Figure 6 The influence of the catalyst amount on the degradation RR141. (Initial dye concentration $=0.1 \mathrm{~g} / \mathrm{dm}^{3}$, initial $\mathrm{pH}=3.5, \mathrm{H}_{2} \mathrm{O}_{2}$ concentration $=0.267 \mathrm{M}$, and temperature $=333 \mathrm{~K}$ ). a) Decolorization as a function of time, b) Decolorization, \%, and COD removal, $\%$, after a reaction duration of $2 \mathrm{~h}$. 
A decrease of $64 \%$ in COD was reached in the degradation of RR141 within 5 hours using the $\mathrm{UV} / \mathrm{H}_{2} \mathrm{O}_{2}$ advanced oxidation process [37].

COD was reduced from $120 \mathrm{mg} / \mathrm{L}$ to $23 \mathrm{mg} / \mathrm{L}(81 \%)$ in the solar nano-photocatalytic degradation of RR141 using $\mathrm{TiO}_{2}$ [38].

A 37\% removal of TOC was achieved in the photocatalytic degradation of RR141 for the $\mathrm{Zn}_{2} \mathrm{SnO}_{4}$ photocatalyst after $270 \mathrm{~min}$ of sunlight irradiation [39].

A TOC reduction of $29 \%$ was achieved in the degradation of RR141 with a $\mathrm{TiO}_{2}$ coated pebble bed photocatalytic reactor having a solar collector [40].

A COD removal of $100 \%$ was obtained in the electrolyse of an aqueous solution of RR141 with a conductivediamond anode [42].

\section{The influence of the catalyst amount on the degradation} of dye

The effect of the catalyst amount was investigated on the Fenton-like degradation of RR141 using catalyst amounts of $0.15 \mathrm{~g}$ and $0.3 \mathrm{~g}$ for $0.150 \mathrm{dm}^{3}$ dye solution under the following reaction conditions: an initial RR141 concentration of $0.1 \mathrm{~g} / \mathrm{dm}^{3}$, a temperature of $333 \mathrm{~K}$, an initial $\mathrm{pH}=3.5$, an initial $\mathrm{H}_{2} \mathrm{O}_{2}$ concentration $=0.267 \mathrm{M}$. The results are shown in Figure 6. Doubling the amount of catalyst slightly increased the color removal from $97 \%$ to $100 \%$ after 2 hours of reaction. The COD reduction increased from $52 \%$ to $81 \%$ with an increase in the amount of the catalyst. This remarkable increase in COD removal may be attributed to the production of more hydroxyl radicals in the degradation reaction of RR141. Because increasing the catalyst amount provides more active catalytic sites of $\mathrm{Fe}^{2+} / \mathrm{Fe}^{3+}$ species to enhance degradation. A similar trend where the catalyst amount influences the degradation of dye was reported in literature, as well $[2,4,20]$.

\section{Influence of the temperature on the degradation of dye} Experiments were conducted to investigate the effect of temperature on the degradation of an aqueous dye solution at four different temperatures, 298, 313, 323, and $333 \mathrm{~K}$ under the following conditions: an RR141 initial concentration of $0.1 \mathrm{~g} / \mathrm{dm}^{3}$, a catalyst amount of $0.15 \mathrm{~g} /$ $0.150 \mathrm{dm}^{3}$ dye solution, an initial $\mathrm{pH}$ of 3.5 , and an $\mathrm{H}_{2} \mathrm{O}_{2}$ amount of $0.033 \mathrm{M}$ (at which the initial decolorization rate was the highest). The results are presented in Figure 7. It

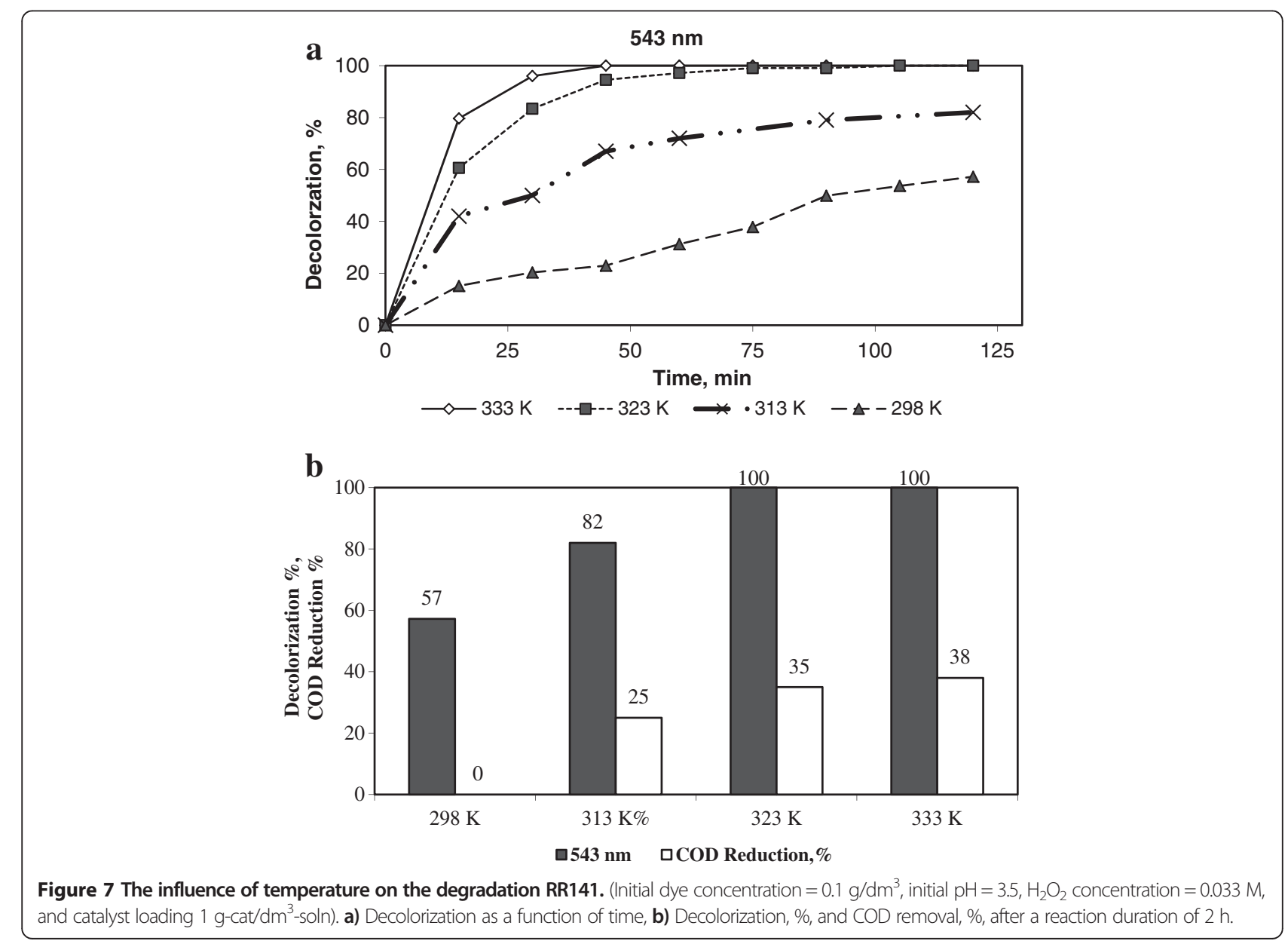




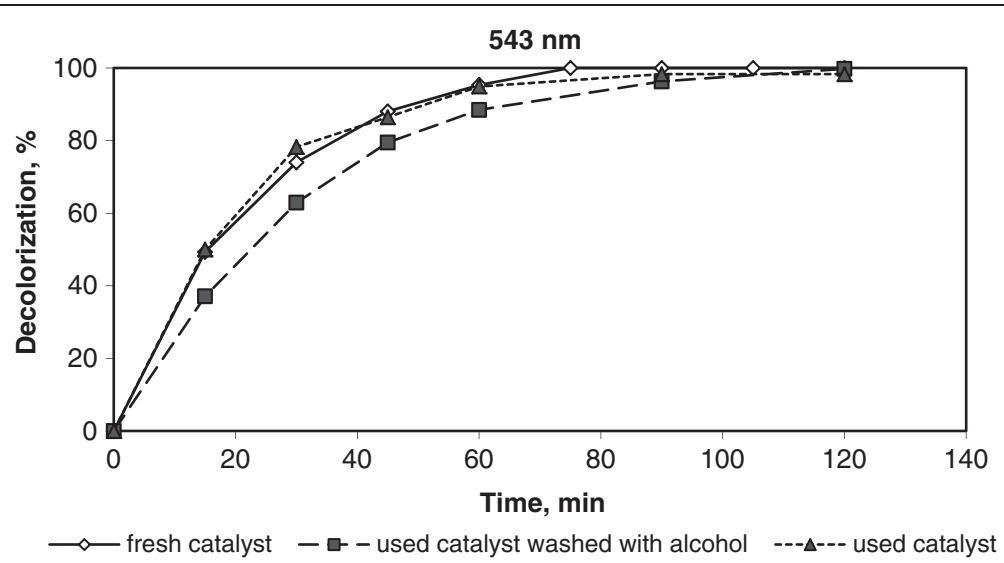

Figure 8 Stability of the catalyst in the oxidation of RR141. (Initial dye concentration $=0.1 \mathrm{~g} / \mathrm{dm}^{3}$, initial $\mathrm{pH}=3.5, \mathrm{H}_{2} \mathrm{O}_{2}$ concentration $=0.033 \mathrm{M}$, catalyst loading $1 \mathrm{~g}$-cat $/ \mathrm{dm}^{3}$-soln, and temperature $=333 \mathrm{~K}$ ).

was clearly seen that the color removal rate increased with the increase in temperature from $298 \mathrm{~K}$ through $313 \mathrm{~K}$ to $323 \mathrm{~K}$ and then to $333 \mathrm{~K}$. These results agree with the fact that the Fenton reaction was accelerated with the increasing temperature, describing an Arrhenius behavior [33]. Because both the collision frequency of the molecules at the surface of the catalyst and the fraction of molecules that possess energy in excess of the activation were increased. Temperature has a significant role at enhancing the extent of the decolorization of dye with the generated $\mathrm{OH}$, since it is a thermodynamic state function that enhances the feasibility of a chemical process [26]. The lowest degradation degree was measured at a temperature of 298 K. Furthermore, while the color removal increased with the increase in temperature no COD reduction was observed at $298 \mathrm{~K}$, however the COD reduction was enhanced with the temperature being $25 \%, 35 \%$, and $38 \%$ at temperatures higher than $298 \mathrm{~K}$, respectively. Regarding the time required to achieve, for instance $40 \%$ of RR141 degradation, it was found that this time significantly decreased when the temperature was increased, with $\mathrm{t}=78.0,14.5,10.0$, and $7.5 \mathrm{~min}$ at $298,313,323$, and $333 \mathrm{~K}$, respectively.

In literature, similar results have been reported in the catalytic wet peroxide oxidation (CWPO) of Orange II over an Fe-saponite catalysts [4], in the CWPO of phenol over pillared clays containing iron [55] and in the wet oxidation of 2.4.6-trichlorophenol in water using an $\mathrm{Fe}^{3+}, \mathrm{Co}^{2+}, \mathrm{Ni}^{2+}$ supported MCM-41 catalysts [18].

\section{Stability of the catalyst}

For the stability studies, the runs were carried out using an $0.15 \mathrm{dm}^{3}$ of $0.1 \mathrm{~g} / \mathrm{dm}^{3} \mathrm{RR} 141$ aqueous solution with an addition of $0.033 \mathrm{M} \mathrm{H}_{2} \mathrm{O}_{2}$ at $333 \mathrm{~K}$, and at a $\mathrm{pH}$ of 3.5. To recover the catalyst, after $2 \mathrm{~h}$ of oxidation the final effluent was filtrated and dried or washed with ethanol and then water. These catalysts were labeled as used catalyst and used catalyst washed with alcohol, respectively. The latter one was calcined by heating to $423 \mathrm{~K}$ and holding there for $15 \mathrm{~min}$ then heating to $873 \mathrm{~K}$ and keeping at this temperature for $2 \mathrm{~h}$ to remove the adsorbed organic species from the active sites $[4,56]$

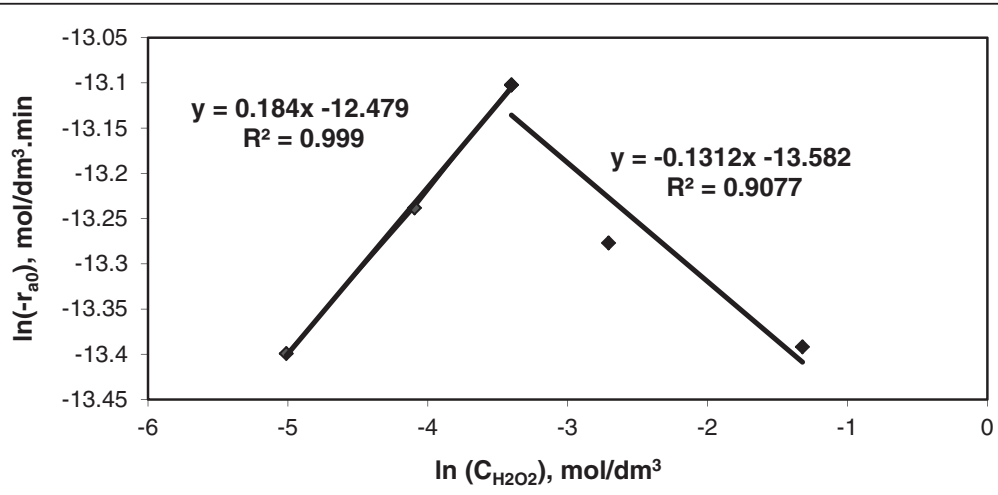

Figure 9 The variation of the initial rate with respect to the initial concentration of $\mathrm{H}_{2} \mathrm{O}_{2}$. 
Table 1 Reaction rate constants at different temperatures

\begin{tabular}{|c|c|c|c|c|}
\hline Temperature $(\mathrm{T}), \mathrm{K}$ & $-r_{A O}\left(m o l / d^{3} \cdot m i n\right)$ & $\mathrm{k}\left(\mathrm{dm}^{3} / \mathrm{mol}\right)^{0,184} \mathrm{~min}^{-1}$ & $\mathrm{C}_{\mathrm{RR} 141}\left(\mathrm{~mol} / \mathrm{dm}^{3}\right)$ & $\mathrm{C}_{\mathrm{H} 2 \mathrm{O} 2}^{0,184}\left(\mathrm{~mol} / \mathrm{dm}^{3}\right)^{0.184}$ \\
\hline 333 & $2.041 * 10^{-6}$ & 0.0677 & $5.64^{*} 10^{-5}$ & 0.535 \\
\hline 323 & $1.708^{*} 10^{-6}$ & 0.0567 & $5.64^{*} 10^{-5}$ & 0.535 \\
\hline 313 & $1.122^{*} 10^{-6}$ & 0.0328 & $5.64^{*} 10^{-5}$ & 0.535 \\
\hline 298 & $4.171 * 10^{-6}$ & 0.0138 & $5.64^{*} 10^{-5}$ & 0.535 \\
\hline
\end{tabular}

and their performances reached in terms of RR141 decolorization are presented in Figure 8. The same color removal results were obtained after $2 \mathrm{~h}$ oxidation of RR141 over fresh, used and used catalyst washed with alcohol. A slight decay in the initial decolorization rate was obtained only on the used catalyst washed with ethanol. The loss of activity can be attributed to the poisoning of the active catalytic sites due to the adsorbed organic species or oxidation of $\mathrm{Fe}^{2+}$ to $\mathrm{Fe}^{3+}$.

In literature, similar results were reported in the studies on the CWPO of Orange II over Fe-saponite catalysts [4] and on CWPO of propionic acid over a FeZSM-5 catalyst [57].

\section{Decolorization kinetics of the Fenton-like oxidation of RR141}

In the Fenton-like oxidation of RR141, the reaction mixture was stirred vigorously at around $280 \mathrm{rpm}$. The external diffusion effects were calculated using Hougen's criterion and it was found that $\left(\mathrm{C}_{\mathrm{b}}-\mathrm{C}_{\mathrm{s}}\right) / \mathrm{C}_{\mathrm{b}} \approx 0.04$, so it was assumed that $\mathrm{C}_{\mathrm{b}} \approx \mathrm{C}_{\mathrm{s}}$. The internal diffusion resistance was negligible due to the small size of the catalyst particles $(500 \mathrm{~nm})$. To calculate the internal diffusion effects, the generalized Thiele modulus based on the reaction rate was determined and found to be $0.339 \times 10^{-6}$ and hence the effectiveness factor was assumed to be unity [58].

The decolorization kinetics was determined at an initial $\mathrm{pH}$ of 3.5 using the initial decolorization rates and a first order dependency was obtained on the dye concentration with $\mathrm{R}^{2}=1$. This result was in good agreement with those reported in literature for decolorization kinetics of RR141 degraded by several advanced oxidation techniques [1,32,34,37,38,40,59]. However, the photo-catalytic degradation of RR141 on $\mathrm{Zn}_{2} \mathrm{SnO}_{4}$ followed the zero order kinetics under sunlight [41].

The order with respect to $\mathrm{H}_{2} \mathrm{O}_{2}$ concentration was determined by plotting the initial rate, $-\ln \left(-\mathrm{r}_{\mathrm{A} 0}\right)$, against the initial $\mathrm{H}_{2} \mathrm{O}_{2}$ concentration, $\ln \left(\mathrm{C}_{\mathrm{H} 2 \mathrm{O} 2,0}\right)$. Figure 9, presents the variation of the initial rate with respect to the initial concentration of $\mathrm{H}_{2} \mathrm{O}_{2}$ for $0.1 \mathrm{~g} / \mathrm{dm}^{3}$ dye concentration at $333 \mathrm{~K}$.

As it is seen in Figure 9, there is a break at the $\mathrm{H}_{2} \mathrm{O}_{2}$ concentration of $0.033 \mathrm{M}$. Namely, order of reaction depends on the amount of $\mathrm{H}_{2} \mathrm{O}_{2}$ (shifting-order reaction). The order of reaction is 0.184 with respect to $\mathrm{H}_{2} \mathrm{O}_{2}$ in the range of $0.007 \mathrm{M}-0.033 \mathrm{M} \mathrm{H}_{2} \mathrm{O}_{2}$ and -0.131 with respect to $\mathrm{H}_{2} \mathrm{O}_{2}$ greater than $0.033 \mathrm{M} \mathrm{H}_{2} \mathrm{O}_{2}$. The initial rate is expressed by equations (8) and (9) based on the amount of $\mathrm{H}_{2} \mathrm{O}_{2}$.

$$
\begin{array}{lc}
-\mathrm{r}_{\mathrm{A} 0}=\mathrm{k} \mathrm{C}_{\mathrm{RR} 141,0} \mathrm{C}_{\mathrm{H} 2 \mathrm{O} 2,0}{ }^{0.184} & (0.007-0.033 \mathrm{M}) \\
-\mathrm{r}_{\mathrm{A} 0}=\mathrm{k} \mathrm{C}_{\mathrm{RR} 141,0} \mathrm{C}_{\mathrm{H} 2 \mathrm{O} 2,0}{ }^{-0.131} & (>0.033)
\end{array}
$$

In these equations, $-r_{\mathrm{A} 0}$ has the units of $\mathrm{mol} / \mathrm{dm}^{3} \mathrm{~min}$, and $\mathrm{C}_{\mathrm{RR} 141,0}$ and $\mathrm{C}_{\mathrm{H} 2 \mathrm{O} 2,0}$ are in units of $\mathrm{mol} / \mathrm{dm}^{3}$, and $\mathrm{k}$ is the reaction rate constant. As seen from Equation 7,

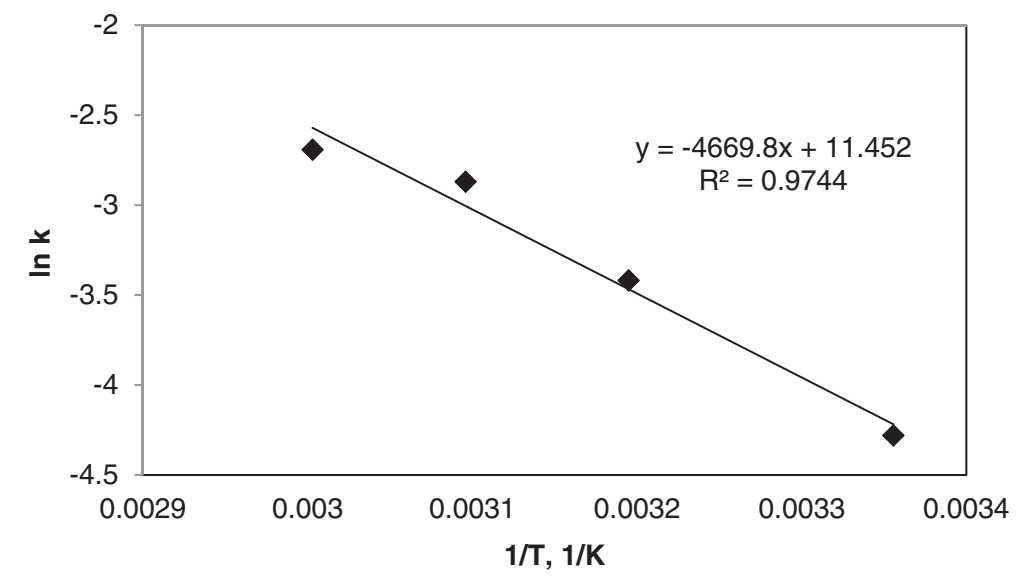

Figure 10 Ink versus 1/T dependency for the decolorization of RR141. 
at high $\mathrm{H}_{2} \mathrm{O}_{2}$ concentrations it reacts with $\mathrm{OH}^{\cdot}$ radicals to generate less reactive perhydroxyl radicals, $\mathrm{HO}_{2}$, causing a decrease in the color removal rate. Table 1 shows the reaction rate constant, $\mathrm{k}$, calculated at different temperatures $(298,313,323$, and $333 \mathrm{~K})$ by using the initial rate equation (8).

Figure 10 presents the Arrhenius plot of lnk vs. 1/T obtained by using the data in Table 1 . From the slope of the Arrhenius plot $\left(R^{2}=0.97\right)$ in Figure $10,-E / R$, where $\mathrm{R}$ is the universal gas constant $(8.314 \mathrm{~J} / \mathrm{mol} \mathrm{K})$, and the activation energy, E, was calculated to be $38.8 \mathrm{~kJ} / \mathrm{mol}$. Finally, the initial decolorization rate of RR141 can be expressed by the following equation for the range of $0.007 \mathrm{M}-0.033 \mathrm{M} \mathrm{H}_{2} \mathrm{O}_{2}$;

$$
-\mathrm{r}_{\mathrm{A} 0}=9.4 * 10^{4} \mathrm{e}^{-38.8 / \mathrm{RT}} \mathrm{C}_{\mathrm{RR} 141,0} \mathrm{C}_{\mathrm{H} 2 \mathrm{O} 2,0} 0.184
$$

In literature, the activation energy for the heterogeneous Fenton-like reaction of RR141 has not been declared. This study is a useful reference in the decolorization kinetics of RR141 for the design of RR141 removal reactors. In the homogeneous photo-Fenton reaction of RR141, activation energy was estimated to be $1.26 \mathrm{~kJ} / \mathrm{mol}$ [34]. The lack of mass transfer resistances facilitates the homogeneous catalytic reactions with low activation energies. Decomposition of RR141 with the ferrioxalate-Fenton/UV-A process was fitted to the empirical Langmuir-Hinshelwood kinetic model [32]. An activation energy of $35.9 \mathrm{~kJ} / \mathrm{mol}$ was reported for the rapid decolorization of azo dye methyl orange in an aqueous solution by nanoscale zerovalent iron particles [60]. This value is very close to the activation energy $(38.8 \mathrm{~kJ} / \mathrm{mol})$ obtained in this study for the heterogeneous Fenton-like oxidation of Reactive Red 141. Moreover, in literature, the activation energy of the homogeneous catalytic Fenton oxidation of Reactive Brillant Blue X-BR azo dye was given to be $25.21 \mathrm{~kJ} / \mathrm{mol}$ [61].

\section{Conclusions}

The heterogeneous Fenton-like degradation of Reactive Red 141 (RR141) in water was investigated over iron containing ZSM-5 zeolite $(\mathrm{Si} / \mathrm{Al}=42)$ prepared by ionexchange. The catalyst seems to have a promising efficiency in RR141 degradation. A complete color removal could be achieved with the catalyst at a pH of 3.5 in an $\mathrm{H}_{2} \mathrm{O}_{2}$ concentration range of $0.007 \mathrm{M}-0.067 \mathrm{M}$ after two hours of reaction. The increase in $\mathrm{H}_{2} \mathrm{O}_{2}$ concentration up to $0.033 \mathrm{M}$ increased the initial decolorization due to the increase of the $\mathrm{OH}$ radicals formed. However, at $\mathrm{H}_{2} \mathrm{O}_{2}$ concentrations higher than $0.033 \mathrm{M}$ the initial decolorization rate of RR141 was decelerated. The highest COD removal was obtained to be $81 \%$ with a complete color removal at an $\mathrm{H}_{2} \mathrm{O}_{2}$ concentration of $0.267 \mathrm{M}$ and at $333 \mathrm{~K}$ with a catalyst amount of $0.3 \mathrm{~g}$ for $0.15 \mathrm{dm}^{3}$ a dye solution of $0.1 \mathrm{~g} / \mathrm{dm}^{3}$. An increase in temperature positively affected the decolorization of dye as well as the COD removal. The initial decolorization rate was described as $-\mathrm{r}_{\mathrm{A} 0}=9.4 * 10^{4} \mathrm{e}^{-38.8 / \mathrm{RT}} \mathrm{C}_{\mathrm{RR} 141,0}$ $\mathrm{C}_{\mathrm{H} 2 \mathrm{O} 2,0}^{0.184}$ in the $\mathrm{H}_{2} \mathrm{O}_{2}$ concentration range of $0.007 \mathrm{M} \mathrm{-}$ $0.033 \mathrm{M}$. Iron leaching remained below the EU directives. The small iron leaching makes it possible for the catalyst to have long term stability without generating iron hydroxide sludge.

It can be concluded that this study offers a significant potential for the application of heterogeneous Fentonlike oxidation over iron containing a ZSM-5 zeolite for the degradation of RR141 aqueous solutions. It will be a good alternative to the oxidation methods currently used in the degradation of RR141.

\section{Competing interests}

The authors declare that they have no competing interests.

\section{Authors' contributions}

CY carried out the experiments under the guidance of GG, participated in the interpretation of the data, helped to draft the manuscript. GG participated in the design of the study, conceived of the study and drafted the manuscript. Both authors read and approved the final manuscript.

\section{Acknowledgement}

The authors acknowledge the financial support from TÜBiTAK (The Scientific and Technological Research Council of Turkey) under Project number of 108 M175 and from the Ege University Scientific Research Fund under project number of 08MÜH023.

Received: 18 April 2014 Accepted: 20 January 2015

Published online: 31 January 2015

\section{References}

1. Tezcanlı-Guyer $\mathrm{G}$, Ince NH. Degradation and toxicity reduction of textile dyestuff by ultrasound. Ultrason Sonochem. 2003;10:235-40.

2. Neamtu M, Zaharia C, Catrinescu C, Yediler A, Macoveanu M, Kettrup M. Fe-exchanged $Y$ zeolite as catalyst for wet peroxide oxidation of reactive azo dye Procion Marine H-EXL. Appl Catal B Environ. 2004;48:287-94.

3. Stolyarova IV, Kovban IB, Prikhod'ko RV, Kushko AO, Sychev MV, Goncharuk W. FeZSM-5 zeolites in oxidative degradation of dyes and the nature of their active centers. Russ J Appl Chem. 2007;80(5):746-53.

4. Ramirez JH, Costa CA, Madeira LM, Mata G, Vicente MA, Rojas-Cervantes ML, et al. Fenton-like oxidation of Orange II solutions using heterogeneous catalysts based on saponite clay. Appl Catal B Environ. 2007;71:44-56.

5. Wailling C. Fenton's reagent revisited. Acc Chem Res. 1975;8:125-31.

6. Neamtu M, Yediler A, Siminiceanu I, Kettrup A. Oxidation of commercial reactive azo dye aqueous solutions by the photo-Fenton and Fenton-like processes. J Photoch Photobio A Chem. 2003;161:87-93.

7. Bertanza G, Collivignarelli C, Pedrazzani R. The role of chemical oxidation in combined chemical-physical and biological processes: experiences of industrial wastewater treatment. Water Sci Technol. 2001;44:109-16.

8. Solozhenko EG, Soboleva NM, Goncharuk W. Decolourization of azo dye solutions by Fenton's oxidation. Water Res. 1995;29:2206-10.

9. Kang SF, Chang HM. Coagulation of textile secondary effluents with Fenton's reagent. Water Sci Technol. 1997;36:215-22.

10. Gemeay AH, Mansour IA, El-Sharkawy RG, Zaki AB. Kinetics and mechanism of the heterogeneous catalyzed oxidative degradation of indigo carmine. J Mol Catal A Chem. 2003;193:109-20.

11. Ishtchenko W, Huddersman KD, Vitkovskaya RF. Part 1. Production of a modified PAN fibrous catalyst and its optimisation towards the decomposition of hydrogen peroxide. Appl Catal A Gen. 2003;242:123-37.

12. Letaief S, Casal B, Aranda P, Martín-Luengo MA, Ruiz-Hitzky E. Fe-containing pillared clays as catalysts for phenol hydroxylation. Appl Clay Sci. 2003;22:263-77.

13. Tachiev G, Roth JA, Bowers AR. Kinetics of hydrogen peroxide decomposition with complexed and "free" iron catalyst. Int J Chem Kinet. 2000;32:24-35. 
14. Martínez F, Calleja G, Melero JA, Molina R. Heterogeneous photo-Fenton degradation of phenolic aqueous solutions over iron-containing SBA-15 catalyst. Appl Catal B Environ. 2005;60:181-90.

15. Bahmani P, Kalantary RR, Esrafilli A, Gholami M, Jafari AJ. Evaluation of Fenton oxidation process coupled with biological treatment for the removal of reactive black 5 from aqueous solution. J Environ Health Sci Eng. 2013;11(13):1-9.

16. Zazouli MA, Yousefi Z, Eslami A, Ardebilian B. Municipal solid waste landfill leachate treatment by Fenton, photı-Fenton and Fenton-like processes: effect of some variables. Iran J Environ Health Sci Eng. 2012;9(3):1-9.

17. Phu NH, Hoa TTK, Van Tan N, Thang HV, P H, Le K. Characterization and activity of Fe-ZSM-5 catalysts for the total oxidation of phenol in aqueous solutions. Appl Catal B Environ. 2001;34:267-75.

18. Chaliha S, Bhattocharyya KG. Wet oxidative method for removal of 2,4,6-trichlorophenol in water using Fe(III), Co(II), Ni(II) supported MCM-41 catalysts. J Hazard Mater. 2008;150:728-36.

19. Dükkancı M, Gündüz G, Yılmaz S, Yaman YC, Prihod'ko RV, Stolyarova IV. Characterization and catalytic activity of CuFeZSM-5 catalysts for oxidative degradation of Rhodamine $6 \mathrm{G}$ in aqueous solutions. Appl Catal B Environ. 2010;95:270-8

20. Dükkancı M, Gündüz G, Yılmaz S, Prihod'ko RV. Heterogeneous Fenton-like degradation of Rhodamine $6 \mathrm{G}$ in water using CuFeZSM-5 zeolite catalyst prepared by hydrothermal synthesis. J Hazard Mater. 2010;181:343-50.

21. Bolova E, Gündüz G, Dükkancı M, Yılmaz S, Yaman YC. Fe Containing ZSM-5 Zeolite as Catalyst for Wet Peroxide Oxidation of Orange II. Int J Chem React Eng. 2011;9:S1.

22. Flores RG, Andersen SLF, Maia LKK, Jose HJ, Moreira RFPM. Recovery of iron oxides from acid mine drainage and their application as adsorbent or catalyst. J Environ Manage. 2012;111:53-60.

23. Chen $\mathrm{A}, \mathrm{Ma} X$, Sun $\mathrm{H}$. Decolorization of $\mathrm{KN}-\mathrm{R}$ catalyzed by Fe containing $Y$ and ZSM-5 zeolites. J Hazard Mater. 2008;156:568-75.

24. Prihod'ko R, Stolyarova I, Gündüz G, Taran O, Yashnik S, Parmon V, et al. Fe exchanged zeolites as materials for catalytic wet peroxide oxidation. Degradation of Rodamine G dye. Appl Catal B Environ. 2011;104:201-10.

25. Rache M, Garcia AR, Zea HR, Silva AMT, Madeira LM, Ramirez JH. Azo-dye orange II degradation by the heterogeneous Fenton-like process using a zeolite Y-Fe catalyst- Kinetics with a model based on the Fermi's equation. Appl Catal B Environ. 2014;146:192-200.

26. Azmi NHM, Ayodele OB, Vadivelu VM, Asıf M, Hameed BH. Fe-modified local clay as effcetive and reusable heterogeneous photo-Fenton catalyst for the decolorization of Acid Green 25. J Taiwan Inst Chem Eng. 2014;45:1459-67.

27. O'Neil C, Lopez A, Esteves S, Hawkes FR, Hawkes DL, Wilcox S. Azo-dye degradation in an anaerobic-aerobic teratment system operating on simulated textile effluent. Appl Microbial Biotechnol. 2010;53:249-54

28. Bell J, Buckley CA. Treatment of a textile dye in the anaerobic baffled reactor. Water SA. 2003;29(2):34

29. Telke A, Kalyani D, Jadhav J, Govindwar S. Kinetics and mechanism of Reactive Red 141 degradation by a banterial Isolate Rhizobium radiobacter MTCC 8161. Acta Chim Slov. 2008:55:320-9.

30. Netpradit S, Thiravetyan P, Towprayoon S. Adsorption of three azo dyes by metal hydroxide sludge: effect of temperature, $\mathrm{pH}$ and electrolytes. J Colloid Interf Sci. 2004;270:255-61.

31. Dolphen R, Sakkyawong N, Thiravetyan P, Nakbanpote W. Adsorption of Reactive Red 141 from wastewater onto modified chitin. J Hazard Mater. 2007;145:250-5.

32. Arslan İ, Balcıoğlu IA, Bahnemann DW. Advanced chemical oxidation of reactive dyes in simulated dye house effluents by ferrioxalate-Fenton/UV-A and $\mathrm{TiO}_{2} /$ UV-A processes. Dyes Pigments. 2000;47:207-18.

33. Torrades F, Garcia-Montano J, Garcia-Hortal JA, Nunez L, Domenech X, Peral J. Decolorisation and mineralization of homo and hetero-bireactive dyes under Fenton and photo Fenton conditions. Color Technol. 2004;120:188-94.

34. Nunez L, Garcia-Hortal JA, Torrades F. Study of kinetic parameters related to decolourization and mineralization of reactive dyes from textile dyeing using Fenton and photo-Fenton processes. Dyes Pigments. 2007;75:647-52.

35. Garcia-Montano J, Perez-Estrada L, Oller I, Maldonado MI, Torrades F. Pilot plant scale reactive dyes degradation by solar photo-Fenton and biological processes. J Photoch Photobio A Chem. 2008;195:205-14.

36. Gültekin I, Ince NH. Degradation of Reactive Azo Dyes by $U V / \mathrm{H}_{2} \mathrm{O}_{2}$ : Impact of radical scavengers. J Environ Sci Heal A. 2004;39(4):1069-81.
37. Racyte J, Rimeika M. UV/ $\mathrm{H}_{2} \mathrm{O}_{2}$-Advanced Oxidation processes possibilities for textile reactive dyes decolorization. Lithuania: The 7th Int. Conference Faculty of Environmental Eng., Vilnius Gediminas Technical Univ., May 22-28; 2008. p. 684-9.

38. Jeni J, Kanmani S. Solar Nanophoto catalytic decolorisation of reactive dyes using titanium dioxide. Iran J Environ Health Sci Eng. 2011;1(8):15-24.

39. Foletto EL, Battiston S, Simoes JM, Bassaco MM, Pereira LSF, Moraes Flores $\mathrm{EM}$, et al. Synthesis of $\mathrm{ZnAl}_{2} \mathrm{O}_{4}$ nanoparticles by different routes and the effcet of its pore size on the photocatalytic process. Micropor Mesopor Mat. 2012;163:29-33.

40. Rao NN, Chaturvedi V, Li PG. Novel pebblebed photocatalytic reactor for solar treatment of textile wastewater. Chem Eng J. 2012;184:90-7.

41. Foletto EL, Simoes JM, Mazutti MA, Jahn SL, Muller El, Pereira LSF, et al. Application of $\mathrm{Zn}_{2} \mathrm{SnO}_{4}$ photo catalyst prepared by microwave-assisted hydrothermal route in the degradation of organic pollutant under sunlight. Ceram Int. 2013;39:4569-74.

42. Aquino JM, Rodrigo MA, Rocha-Filho RC, Saerz C, Carizares F. Influence of the supporting electrolyte on the electroyses of dyes with conductive-diamond anodes. Chem Eng J. 2012;184:221-7.

43. Harrelkas F, Azizi A, Yaacoubi A, Benhammou A, Pons MN. Treatment of textile dye effluents using coagulation-flocculation coupled with membrane proxesses or adsorption on powdered activated carbon. Desalination. 2009:235:330.

44. Kasiri MB, Aleboyeh $\mathrm{H}$, Aleboyeh A. Degradation of Acid Blue 74 using Fe-ZSM-5 zeolite as a heterogeneous photo-Fenton catalyst. Appl Catal B Environ. 2008;84:9-15.

45. Hassan $\mathrm{H}$, Hameed BH. Oxidative decolorization of Acid Red 1 solutions by Fe-zeolite $Y$ type catalyst. Desalination. 2011;276:45-52.

46. Jamalludin NA, Abdullah AZ. Low frequency sonocatalytic degradation of azo dye in water using Fe-doped zeolite $Y$ catalyst. Ultrason Sonochem. 2014;21:743-53.

47. Aleksik M, Koprivanae N, Bozic AL, Kusic H. The potential of Fe-exchanged $Y$ zeolite as a heterogeneous Fenton-type catalyst for oxidative degradation of Reactive Dye in water. Chem Biochem Eng Q. 2010;24:309-19.

48. Alwash $\mathrm{AH}$, Abdullah $\mathrm{AZ}$, Ismail $\mathrm{N}$. Zeolite $\mathrm{Y}$ encapsulated with $\mathrm{Fe} / \mathrm{TiO}$, for ultrasound-assisted degradation of amaranth dye in water. J Hazard Mater. 2012;233-234:184-93.

49. Xu HY, He XL, Wu Z, Shan LW, Zhang WD. Iron-loaded natural clay as heterogeneous catalyst for Fenton-like discolorization of dyeing wastwater. Bull Kor Chem Soc. 2009;30:2249-52.

50. Hassan $\mathrm{H}$, Hameed BH. Fe-clay as effective heterogeneous Fenton catalyst for the decolorization of Reactive Blue 4. Chem Eng J. 2011;171:912-8.

51. Hassan H, Hameed BH. Fenton-like oxidation of Acid Red 1 solutions using heterogeneous catalyst based on ball clay. Int J Environ Sci Dev. 2011;2(3):1-3.

52. Bankovic P, Nikolic AM, Mojovic Z, Jovicic NJ, Zunic M, Dondur V, et al. Al, Fe-pillared clays in catalytic decolorization of aqueous tartrazine solutions. Appl Clay Sci. 2012;58:73-8.

53. Yaman YC, Gündüz G, Dükkancı M. Degradation of C.I. Reactive Red 141 by heterogeneous Fenton-like process over iron containing ZSM-5 zolites. Color Technol. 2013;29:69-75.

54. Schwidder M, Kumar MS, Klementiev K, Pahl MM, Brückner A, Grünert W. Selective reduction of $\mathrm{NO}$ with Fe-ZSM-5 catalysts of low Fe content: I. Relations between active site structure and catalytic performance. J Catal. 2005;231:314-30

55. Guelou E, Barrault J, Fournier J, Tatibouet J-M. Active iron species in catalytic wet peroxide oxidation of phenol over pillared clays containing iron. Appl Catal B Environ. 2003:44:1-8.

56. Catrinescu C, Teodosiu C, Macoveanu M, Miehe-Brende J, Dred RL. Catalytic wet peroxide oxidation of phenol over Fe-exchanged pillared beidellite. Water Res. 2003;37:1154-60.

57. Centi R, Parathoner S, Torre T, Verduna MG. Catalytic wet oxidation with $\mathrm{H}_{2} \mathrm{O}_{2}$ of carboxylic acids on homogeneous and heterogeneous Fenton-type catalysts. Catal Today, 2000:55:61-9.

58. Smith JM. Chemical Engineering Kinetics, McGrow Hill. 3rd ed. 1981. p. 405-84.

59. Neamtu M, Siminiceanu I, Yediler A, Kettrup A. Kinetics of decolorization and mineralization of reactive azo dyes in aqueous solution by the $U V / \mathrm{H}_{2} \mathrm{O}_{2}$ oxidation. Dyes Pigments. 2002;53:93-9. 
60. Fan J, Guo Y, Wang J, Fan M. Rapid decolorization of azo dye Methyl Orange in aqueous solution by nanoscale zerovalent iron particles. J Hazard Mater. 2009;166:904-10.

61. Xu H, Zhang D, Xu W. Monitoring of decolorization kinetics of Reactive Brilliant Blue X-BR by aniline spectrophotometric method in Fenton oxidation process. J Hazard Mater. 2008;158:445-53.

Submit your next manuscript to BioMed Central and take full advantage of:

- Convenient online submission

- Thorough peer review

- No space constraints or color figure charges

- Immediate publication on acceptance

- Inclusion in PubMed, CAS, Scopus and Google Scholar

- Research which is freely available for redistribution 